\title{
Reactivation of neurocysticercosis: calcified nodular lesion and perilesional edema
}

\author{
Larissa Grazielle Souza Ribeiro[1] ${ }^{\circledR}$, Helen Cristina Marcusso ${ }^{[1]}$ ๑ \\ and Lucas Giansante Abud ${ }^{[2]} \odot$
}

[1]. Hospital São Francisco, Documenta Centro Avançado de Diagnóstico por Imagem, Unidade Ribeirão Preto, SP, Brasil.

[2]. Hospital São Lucas, Medicina Diagnóstica, Ribeirão Preto, SP, Brasil.
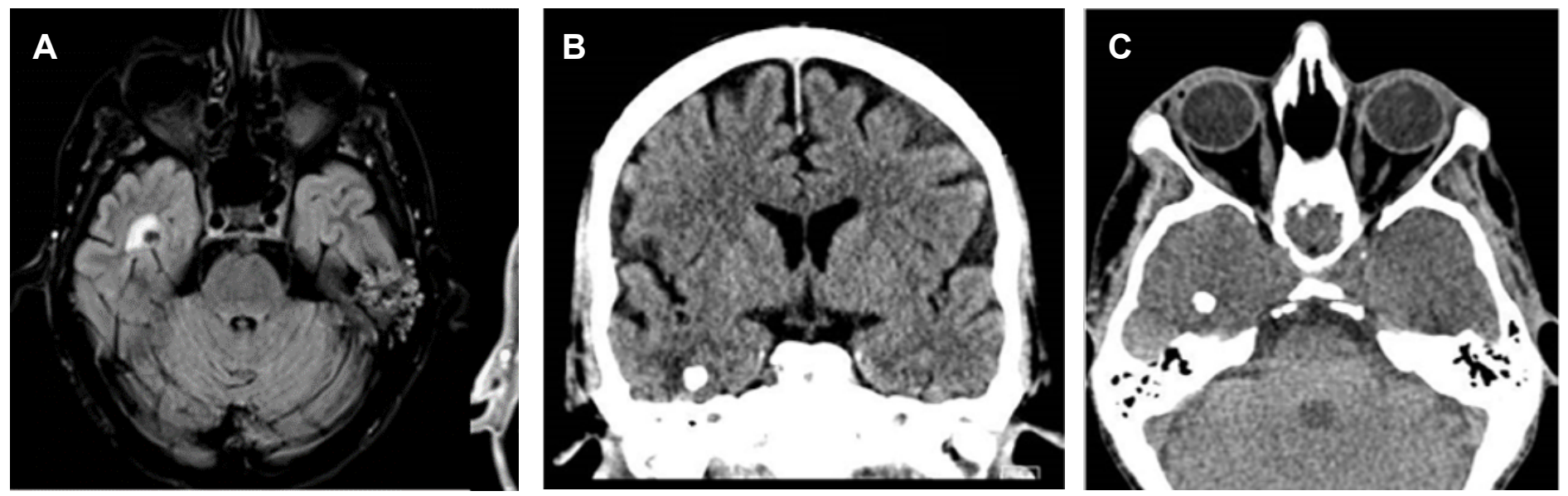

A 53-year-old man presented to the emergency department with headache and seizures. Axial fluid-attenuated inversion recovery (FLAIR) magnetic resonance imaging (MRI) revealed a nodular focus in the right temporal lobe with a halo of T2 hyperintensity (Figure A). Computed tomography (CT) confirmed a calcified image with edema (Figure B). The patient's symptoms improved with clinical treatment, and CT after 7 months showed maintenance of cerebral calcification with the disappearance of edema, suggesting total regression of the inflammation (Figure C). Neurocysticercosis (NCC) develops after the ingestion of Taenia solium eggs and represents the parasitic disease with the greatest tropism for the human central nervous system ${ }^{1}$. It is the most prevalent cause of acquired epilepsy and is a major public health problem worldwide ${ }^{1,2}$. Calcifications, which represent the final stage, are the most common radiological findings among NCC cases. The presence of perilesional edema around a calcification supports the diagnosis of NCC reactivation, which can lead to headaches, seizures, and disabling epilepsy ${ }^{2,3}$. Some hypotheses can explain the reactivation of the disease. For example, perilesional edema may have resulted from the death of parasites that were still viable and incompletely calcified ${ }^{2,3}$. Another possibility is the release of antigens from dead cysticerci, which, for unclear reasons, can be recognized by the host, triggering an inflammatory response ${ }^{2}$. Regardless of the explanation, clinicians and radiologists should know that patients with calcified lesions may experience NCC reactivation ${ }^{2}$. Thus, this diagnosis should be made using imaging findings, and prompt care support must be provided to avoid unfavorable outcomes.

Corresponding author: Larissa Grazielle Souza Ribeiro. e-mail: larissagsribeiro@hotmail.com

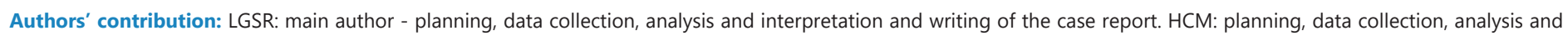
interpretation, and writing of the case report. LGA: planning, data collection, analysis and interpretation, writing and review of the manuscript.

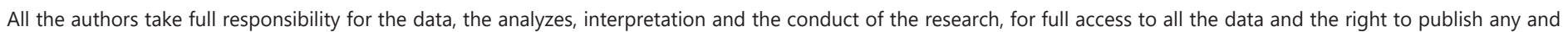
all of them.

Conflict of Interest: The authors declare that there is no conflict of interest. 


\section{ACKNOWLEDGMENTS}

We offer our deepest thanks to the institutions that provided technical support for the development and implementation of this study.

\section{REFERENCES}

1. Kimura-Hayama ET, Higuera JA, Corona-Cedillo R, Chávez-Macías L, Perochena A, Quiroz-Rojas LY, et al. Neurocysticercosis: radiologicpathologic correlation. Radiographics. 2010;30(6):1705-19.
2. Coeli GNM, Tiengo RR, Silva AC, Fernandes JOM, Silva GC, Silva LUMA. Neurocisticercose nodular calcificada com sinais de reativação. Radiol Bras. 2012;45(5):291-3.

3. Lino-Junior RS, Faleiros ACG, Vinaud MC, Oliveira FA, Guimarães JV, Reis MA, et al. Anatomopathological aspects of neurocysticercosis in autopsied patients. Arq Neuropsiquiatr. 2007;65(1):87-91.

Received 28 October 2021 | Accepted 9 December 2021 